\title{
Interventions to Alleviate Symptoms Related to Breast Cancer Treatments and Areas of Needed Research
}

\author{
Michelle C Janelsins ${ }^{1 *}$, Karen M Mustiann, ${ }^{1,2}$, Luke J Peppone ${ }^{1,3}$, Lisa K Sprod ${ }^{1}$, Michelle Shayne ${ }^{4}$, Supriya Mohile ${ }^{4}$, Kavita Chandwani ${ }^{1}$, \\ Jennifer S Gewandter ${ }^{1}$, Gary R Morrow ${ }^{1,5}$
}

${ }^{1}$ Department of Radiation Oncology, University of Rochester School of Medicine and Dentistry, James P. Wilmot Cancer Center, USA

${ }^{2}$ Department of Community and Preventive Medicine, University of Rochester School of Medicine and Dentistry, James P. Wilmot Cancer Center, USA

${ }^{3}$ Department of Orthopedics, University of Rochester School of Medicine and Dentistry, James P. Wilmot Cancer Center, USA

${ }^{4}$ Department of Medicine, University of Rochester School of Medicine and Dentistry, James P. Wilmot Cancer Center, USA

${ }^{5}$ Department of Psychiatry, University of Rochester School of Medicine and Dentistry, James P. Wilmot Cancer Center, USA

\begin{abstract}
Treatments for breast cancer produce a host of side effects, which can become debilitating. Some cancer treatment-related side effects occur in up to $90 \%$ of patients during treatment and can persist for months or years after treatment has ended. As the number of breast cancer survivors steadily increases, the need for cancer control intervention research to alleviate side effects also grows. This review provides a general overview of recent clinical research studies of selected topics in the areas of symptom management for breast cancer with a focus on cognitive difficulties, fatigue, cardiotoxicity, bone loss, insomnia, and cancer pain. We review both pharmacological and behavioral intervention clinical research studies, conducted with breast cancer patients and survivors. Additionally, clinical perspectives on symptom management and recommendations for areas of needed research are provided.
\end{abstract}

Keywords: Cancer treatment; Symptom management; Side effects; Interventions; Intervention mechanisms

\section{Symptoms Associated with Breast Cancer Treatment Discussed in this Review}

While advances in breast cancer therapies have resulted in improved survival, side effects stemming from these treatments can be persistent and debilitating. Research suggests that chemotherapy, radiation therapy and hormonal therapy can all contribute to the development and persistence of side effects, including cognitive impairment [1-17], fatigue [18-22], sleep difficulty [23], pain [24-27], cardiotoxicity [2829], and bone loss, [30-32] the areas of focus in the current review. Many of these symptoms co-occur; however, the underlying etiological pathways leading to each of these side effects may be distinct. Key pathways likely involved in the development of many treatment-related symptoms include immune system dysfunction, genetic pathways, hypothalamic-pituitary-adrenal axis dysfunction, and apoptosis of non-neoplastic cells [33-44].

Side effects from breast cancer treatments can negatively influence quality of life and activities of daily living, lead to non-compliance treatments, and ultimately affect prognostic and survival outcomes $[45,46]$. Interventions to alleviate side effects are needed to reduce symptom burden, enhance quality of life and functional capacity, and improve adherence to therapy. This review summarizes recent clinical trials and other clinical research studies in the areas of symptom management for breast cancer with a focus on cognitive difficulties, fatigue, cardiotoxicity, bone loss, insomnia, and cancer pain.

\section{Pharmacological Interventions to Treat Symptoms in Breast Cancer}

\section{Psychostimulants}

Methylphenidate, which enhances levels of dopamine in the brain, is commonly used to treat attention deficit disorder. Several randomized controlled trials have assessed the effects of methylphenidate or its derivatives in trials of cancer-related fatigue and have revealed some promising preliminary results, although these studies have been conducted with relatively small samples. Bruera and colleagues [47] found significant improvements in fatigue in both methylphenidate and placebo groups. Lower and colleagues demonstrated that dexmetheylphenidate, the D-isomer of methylphenidate, led to a significant reduction in fatigue in patientswho had received chemotherapy [48]. Auret and colleagues showed that the psychostimulant dexamphetamine had no significant effect on fatigue compared to placebo [49].

Modafinil is a wakefulness-promoting agent that is effective in treating sleep disorders and has also been shown to have cognitionenhancing functions. Modafinil can alleviate cancer-related cognitive difficulties (i.e. speed of memory, episodic memory quality) in breast cancer survivors [50]. In patients receiving chemotherapy, modafinil also reduced severe fatigue but had no benefit in those with mild or moderate fatigue [51]. Interestingly, in that same study modafinil did not improve depression, suggesting that while some symptoms, like fatigue and depression,co-occur, they may have underlying distinct pathways and warrant separate interventions.

\section{Selective serotonin reuptake inhibitors}

Selective serotonin reuptake inhibitors (SSRIs) are typically used

*Corresponding author: Michelle C Janelsins, PhD, Research Assistant Professor, University of Rochester Medical Center, James P. Wilmot Cancer Center, Department of Radiation Oncology, 265 Crittenden Boulevard, Box 658, Rochester, NY 14642, USA, Tel: 585-276-4656; Fax: 585-461-5601; E-mail: Michelle_janelsins@urmc.rochester.edu

Received May 12, 2011; Accepted September 12, 2011; Published September 29, 2011

Citation: Janelsins MC, Mustian KM, Peppone LJ, Sprod LK, Shayne M, et al. (2011) Interventions to Alleviate Symptoms Related to Breast Cancer Treatments and Areas of Needed Research. J Cancer Sci Ther S2. doi:10.4172/1948-5956. S2-001

Copyright: (C) 2011 Janelsins MC, et al. This is an open-access article distributed under the terms of the Creative Commons Attribution License, which permits unrestricted use, distribution, and reproduction in any medium, provided the original author and source are credited. 
as anti-depressants to treat depressive and anxiety disorders. Recent studies have been conducted to assess the effects of paroxetine on cancer-related fatigue. Two studies have shown that paroxetine alleviated depression but not fatigue in breast cancer patients receiving chemotherapy [52,53], and another study showed that paroxetine is as good as amitriptyline for treating depressive symptoms in cancer patients [54]. Paroxetine represents another interesting example where alleviating one symptom does not alleviate another.

\section{Vitamin D}

In recent years, many studies have examined the relationship between breast cancer outcomes and vitamin D. Vitamin D also plays an important role in breast cancer symptom management. Vitamin D supplementation may reduce cancer-treatment-induced bone loss, aromatase inhibitor-induced arthralgias, cognitive difficulties, and cardiotoxicity. Nevertheless, vitamin D deficiency/insufficiency $(<30$ $\mathrm{ng} / \mathrm{ml}$ ) remains highly prevalent in breast cancer patients, with rates of sub-optimal vitamin D levels ranging from $63-90 \%[55,56]$.

Up to $80 \%$ of breast cancer patients experience bone loss during treatment [30-32]. While postmenopausal women without cancer lose an annual average of $1 \%$ of their bone mineral density (BMD), women receiving treatment for breast cancer can lose $2 \%$ to $7 \%$ of their BMD annually [57-61], resulting in a 5-fold increased rate of fractures compared to women without cancer [62-64]. Bone loss and the ensuing fractures result in increased mortality, increased need for assisted living, and decreased quality of life [65-68]. The major role of vitamin $\mathrm{D}$ in humans is to increase the absorption of calcium and phosphate, which are directly involved in the development and maintenance of the skeleton [69]. The majority of vitamin D is produced in the skin in response to sunlight exposure. When sunlight exposure is limited (e.g. winter months, sunscreen usage), dietary sources such as fatty fish, fortified foods, and supplements become the main source of vitamin D [70]. Randomized controlled clinical trials show that vitamin D supplementation can improve bone metabolism, increase BMD, and decrease fracture incidence [71-74]. Trials in postmenopausal women show that the beneficial bone effects of vitamin D supplementation are strongly dose-dependent [71], with vitamin D supplementation doses $<500 \mathrm{IU} /$ day failing to significantly improve bone metabolism biomarkers (BMB) and BMD levels [75-77]. Significant improvements in bone health with higher daily doses of vitamin D (500-1,200 IU/day) have been observed $[73,74,78,79]$, while other studies found no benefit [80-82]. Only a small number of studies have examined the effect of high-dose, weekly vitamin D supplementation (20,000-100,000 IU/ week) on bone health, but these studies have yielded positive results in terms of improvements in bone metabolism and BMD levels [83-87]. While strong evidence supports the use of vitamin D supplementation in the preservation bone health, there is no consensus on the ideal amount of vitamin D intake, and further trials are needed to determine the ideal vitamin D supplementation regimen for the prevention of bone loss.

Recent studies have shown that cognitive impairment affects a large number of breast cancer patients and survivors, specifically impacting memory and concentration [88]. In the nervous system, vitamin $\mathrm{D}$ functions as a neurosteroid hormone and displays antineurodegenerative actions [89-91]. Observational studies show increased vitamin D levels are associated with increased global cognitive function $[90,92,93]$. While no clinical trials examining the effect of vitamin D supplementation on cognitive function exist to date, vitamin $\mathrm{D}$ supplementation remains a promising treatment for the prevention and alleviation of cognitive impairment in breast cancer patients and further research in this area is needed. Arthralgia (joint pain) is a well-characterized side effect of aromatase inhibitor (AI) therapy [94]. Phase III AI trials indicate that $18-35 \%$ of patients complain of arthralgias [24-27], while almost $50 \%$ of AI users reported arthralgias in cross-sectional surveys [95]. Arthralgias are the number one reason for non-compliance in AI users [96,98], with up to $25 \%$ of AI users discontinuing usage [97,98]. Two recent studies have shown high-dose vitamin D supplementation significantly reduces AI-induced arthralgias. One study found that breast cancer patients who reached the target threshold for vitamin D (25-OH vitamin D > $40 \mathrm{ng} / \mathrm{ml}$ ) had an $88 \%$ reduction in the onset of AI-induced arthralgias when compared to those who did not reach the target threshold [99]. The other study found that breast cancer patients who were above the median $25-\mathrm{OH}$ vitamin $\mathrm{D}$ level $(>66 \mathrm{ng} / \mathrm{ml})$ reported no disability from joint pain $52 \%$ of the time while those below the median $25-\mathrm{OH}$ vitamin D level ( $<66 \mathrm{ng} / \mathrm{ml})$ reported no disability from joint pain only $19 \%$ of the time. While further research is needed, vitamin D shows initial promise in the prevention of AI-induced arthralgias.

Cardiotoxicity refers to a diverse range of cardiovascular effects, including heart failure, myocardial infarction, pericardial disease, valvular abnormalities, due to anti-neoplastic therapy [100]. Cardiovascular mortality of cancer survivors is 7 -fold higher than the age-matched non-cancer population $[28,29]$. Anthracyclines, a key component of numerous cytotoxic regimens, is one of the main causes of cardiotoxicity in breast cancer patients [101]. Symptoms of cardiotoxicity, such as decreased left ventricular function, are seen in approximately $25 \%$ of breast cancer patients treated with anthracyclines [102]. Trastuzumab, a monoclonal antibody used in the treatment of HER2-positive breast cancer, also contributes to cardiotoxicity. Cardiotoxicity is seen in 3-7\% of patients who use Trastuzumab alone and close to $30 \%$ when it is combined with anthracyclines [103]. Large randomized trials are currently under way evaluating the effect of vitamin D supplementation on cardiovascular outcomes [104]. Based on the evidence of ongoing trials, vitamin D supplementation may eventually be used as a cardioprotective agent in breast cancer patients.

\section{Pharmacologic Interventions for Neuropathic Pain Related to Surgery}

Between 20 and $50 \%$ of breast cancer patients develop chronic neuropathic pain in the breast, axilla, and arm [105-107] Pharmacological interventions for neuropathic pain include opioid analgesics, antidepressants, and anti-epileptic drugs (reviewed in 108). Few drugs have been systematically tested in randomized clinical trials for efficacy specifically in post-mastectomy/ lumpectomy pain (PMLP). However, gabapentin, an antiepileptic drug, and venlafaxine, a serotonin-norepinephrine reuptake inhibitor (SNRI), have proven effective in multiple trials involving PMLP. Both drugs decreased existing chronic pain in women who had previously received breast cancer surgery [109-110]. When administered starting before surgery, gabapentin decreased the time to first post-operative analgesic as well as pain scores and adjuvant analgesic use within the first 10 days. However, no effect was observed on long-term chronic pain in the two studies that inquired 3 and 6 months post-surgery [111-113]. However, treatment with venlafaxine beginning prior to surgery decreased pain scores and the need for analgesic use 6 months after surgery in two separate trials $[111,114]$. Venlafaxine decreased analgesic consumption between 2 and 10 days post-surgery in 1 out of the 2 studies [111]. An eutectic cream mixture of local anesthetics (EMLA) also demonstrated 
promise as a pre-surgical treatment preventing chronic post-operative pain. When applied to the breast and arm area beginning one day prior to surgery, EMLA decreased analgesic consumption between 2 and 6 days post-surgery and the incidence and intensity of pain 3 months after surgery [115]. Similar results were obtained when the same investigators combined EMLA and gabapentin in pre-operative treatment [116]

Addition of a paravertebral nerve block (PVB) anesthetic component during breast cancer surgery has been reported to decrease acute pain and opiod consumption immediately following surgery in multiple randomized clinical trials [117-120]. However, the effects of PVB implementation on pain levels and analgesic consumption after discharge vary between studies. Kairaluoma et al. $[117,118]$ reported decreased pain at 14 days as well as 6 and 12 months after surgery in their PVB group. Conversely, Boughey et al. [121] detected differences at 1 and 3 hours post surgery, but not at one week. Moller et al. [119] reported significant differences in median pain intensity in the postanesthesia care unit (PACU), but not after discharge. However, the very low pain levels in all study participants after discharge decreased the probability of detecting significant differences. Together these studies suggest that the use of PVB is beneficial for acute post-operative pain in breast cancer patients; however refinement of study methods and dosage are needed to provide prolonged effects and reduced PMLP.

\section{Behavioral Interventions to Treat Symptoms in Breast Cancer}

\section{Exercise}

Exercise is a systematic, organized, and consistent routine of participating in physical activity at a dose (frequency, intensity, duration and mode) sufficient to produce improvements in physical (e.g., neurological, cardiovascular, pulmonary, muscular, bone) and/ or psychological (e.g., memory, concentration, fatigue, sleep, anxiety, depression) health $[123,124]$. Exercise can be individually tailored and shows great promise as an intervention capable of improving many side effects stemming from breast cancer and its treatments such as neurotoxicity, impaired immune function, cardiopulmonary toxicities, bone loss, cognitive problems, fatigue, sleep disruption, anxiety, and depression [123-135]. As mentioned earlier in this review, side effects can be acute (starting during treatment and of relatively short duration), chronic (lasting for longer durations i.e., months or years), or late (developing months or years after treatments are completed) and evidence supports the use of exercise to minimize each of these types of side effects [123-135].

\section{Aerobic exercise}

Running, cycling, swimming, and walking are modes of aerobic exercise [136]. Research shows exercise to be a valuable intervention for the reduction of many breast cancer and treatment related side effects such as cognitive problems, fatigue, sleep disruption, depression, anxiety, self-esteem, cardiopulmonary function, immune function, body composition, muscular strength, and flexibility as well as many other side effects [122-125,131,134,137-150].

Aerobic exercise can be beneficial when performed during and after treatment. Summaries of a few of these studies are highlighted. Mock and colleagues [151-153] reported that during chemotherapy and radiation for breast cancer, patients who performed home-based walking at a moderate intensity (50-70\% of maximum heart rate) reported reductions in cancer-related fatigue CRF, sleep disruption, depression, anxiety, and nausea with improvements in cardiopulmonary function, and QOL. Home-based walking was performed for 10 to 45 minutes per day, 4 to 6 days per week, for one to six months. Female breast cancer survivors undergoing chemotherapy concurrent with participation in an aerobic exercise intervention which was progressive in nature, beginning with 15 minutes per session at $60 \%$ of $\mathrm{VO}_{2}$ peak for 3 sessions per week and progressing to 45 minute sessions at $80 \%$ of $\mathrm{VO}_{2}$ peak, using a treadmill, cycle ergometer, or elliptical trainer showed improvements in anxiety [154]. Courneya and colleagues [154] also found that breast cancer patients who were undergoing chemotherapy treatments could tolerate a higher relative dosage of chemotherapy treatment if performing aerobic exercise [154]. A study of breast cancer survivors who had completed treatment were given a moderate intensity home-based walking exercise intervention in which they walked 2 to 5 days per week for 12 weeks at 55 to $65 \%$ of maximum heart rate. Compared to control group participants, the exercise group reported improvements in fatigue, mood, vigor, and body esteem [155]

\section{Resistance exercise}

Resistance exercise can come in many forms, including dumbbells, therapeutic resistance bands, or even body weight [136]. Resistance training exercises have been found to benefit breast cancer survivors when performed during and following cancer treatment [122125,131,134,137-150]. For example, during chemotherapy treatment for breast cancer, performing resistance training that consisted of 2 sets of 8 to 12 repetitions, three times per week, for the duration of chemotherapy resulted in an increase in self-esteem, upper and lower body strength, and lean body mass when compared to a usual care control group and. Further, exercising patients could tolerate higher doses of chemotherapy [154]. Schmitz and colleagues [141] studied the safety and efficacy of resistance training in breast cancer survivors who had recently completed primary treatment. The twice weekly resistance training for 6 to 12 months was safe and resulted in decreased body fat and increased lean body mass. Similarly, Ahmed and colleagues [156] assessed the safety of resistance training for breast cancer survivors who had recently completed treatment. Six months of twice weekly resistance training did not result in any change in arm circumference in participants. A progressive, moderate intensity resistance training and impact training (jump exercises), preformed 3 times per week for 1 year, has been found to preserve bone mineral density in the lumbar spine of breast cancer survivors who are taking aromatase inhibitors, when compared to a control condition [157].

\section{Combined aerobic and resistance exercise}

Exercise programs that combine aerobic exercise and resistance training among breast cancer patients and survivors also effectively for reduce side effects [122-125,131,134,137-150]. A few of these studies are presented. Early stage breast cancer survivors receiving chemotherapy and/or radiation who participated in an aerobic and resistance exercise intervention 2 days a week for 12 weeks reported improvements in CRF, QOL, satisfaction with life, and also improved in physical function compared to usual care [156,158]. Mustian and colleagues [159] have also demonstrated the benefits of performing aerobic and resistance exercise during radiation treatment. A four week individually tailored, home based aerobic and resistance training program resulted in improved CRF, QOL, sleep, aerobic capacity, strength and immune function [36,159]. Sprod and colleagues [36] found that breast and prostate cancer patients receiving radiation treatments who exercised for four weeks using the home-based aerobic and resistance training program developed by Dr. Mustian exhibited 
greater improvements in sleep quality than non-exercising controls. Associations between interleukin-6 and sleep efficiency and duration were demonstrated. While undergoing radiation therapy, participants progressively increased the number of steps walked daily from 5,000 to nearly 12,000 [36,159]. Milne and colleagues [160] also used an exercise intervention that combined aerobic and resistance training for 12 weeks that resulted in improved muscular strength and aerobic fitness in breast cancer survivors who had completed treatment.

\section{Mindfulness-based exercise}

Mindfulness-based exercise modes such as Tai Chi Chuan and Yoga provide substantial benefits for cancer patients by relieving side effects, improving physical function and increasing QOL. For example, a community-based 12-week, 15-move, Yang Style ShortForm of Tai Chi Chuan improved aerobic capacity, strength, flexibility, body composition, self-esteem, QOL, bone formation and resorption, and immune function among breast cancer patients post-treatment [128,129,131,161-164].

\section{Exercise for older cancer patients and survivors}

More than $60 \%$ of people diagnosed with cancer are 65 years of age and over, and by 2030 approximately $70 \%$ of cancer patients will be elderly [165]. As cancer survival rates continue to improve, the number of older adults living with a cancer history in the United States will continue to grow. Older cancer survivors, compared to older adults without a cancer history, are at greater risk of developing geriatric syndromes including dementia, depression, osteoporosis, and at a greater risk of falls [166]. Limitations in activities of daily living [166], reduced quality of life [167], and greater frailty [166] are also common in older cancer survivors. Although a majority of cancer patients suffer from a multitude of symptoms and side effects from treatment, younger cancer patients may experience a transient functional decline where as older cancer patients may never fully recover function following treatment [168]. Ongoing research is seeking to identify which assessment tools can best predict outcomes in this population, and thus guide us in tailoring treatments to maximize benefits in older adults with breast cancer.

Very few researchers have specifically targeted older breast cancer survivors with aerobic and resistance exercise interventions despite the promise of such interventions. LaStayo et al. [169] implemented a 12 week eccentric, lower body exercise intervention in older breast cancer survivors. This eccentric exercise intervention involved the use of a recumbent stepper, with participants instructed to resist the motion of the pedals as they moved toward the participant. The force produced by the stepper was greater than could be overcome, so participants quadriceps in particular, elongating under the force of the stepper. This intervention resulted in increases in knee extension strength and power, and aerobic capacity, and decreased time to safely ascend stairs. Physical activity interventions are recommended for all older adults due to their ability to promote muscle mass and muscular strength [170], improve aerobic capacity [171], and reduce falls [172-174]. It is recommended that older adults, including older adults with chronic medical conditions such as cancer, participate in regular aerobic and resistance exercise training, including 150 to 300 minutes of aerobic exercise per week and at least 2 days per week of resistance training [175]. In addition, the Panel on Prevention of Falls in Older Persons of the American Geriatrics Society and British Geriatrics Society recommend that older persons incorporate a customized exercise program, including resistance, balance, gait, and coordination training to be most effective for reducing falls [176]. Older breast cancer survivors report reduced physical activity levels during and immediately following treatment but many attempt to reintroduce physical activity into their lives following treatment [177]. However, some barriers to physical activity following treatment include lack of time, fear of developing lymphedema, and complications from reconstructive surgery [177]. Of note, researchers have found breast cancer survivors with at least two lymph nodes removed who participated in a 13 week weight lifting intervention did not develop lymphedema at a greater rate than a control group that did not participate in resistance training [178]. Exercise interventions show great promise as an intervention that may reduce side effects and combat many of the common age related declines, such as reduce muscular strength and balance.

\section{Integrative Medicine Approaches}

Complementary and Alternative medicine (CAM) or integrative medicine, is a broad area of health care modalities that includes all the techniques that are not a part of conventional medicine and are commonly not prescribed by medical doctors or allied health care professionals. CAM includes natural products, mind body medicine, and manipulative and body-based practices. Women with breast cancer have reported using many of these techniques in conjunction with their treatment or after the completion of their treatment as a way of treating or alleviating their symptoms. In fact, breast cancer patients report CAM usage as high as $75 \%$ [179].

Natural products such as herbs, vitamins, and minerals constitute the most widely used CAM techniques among breast cancer patients [180]. Systematic research however, reveals that multivitamins are not helpful in relieving fatigue in breast cancer patients in a double-blind crossover design compared with a placebo [181]. A Significan effect of a Chinese herbal combination on reducing chemotherapy-induced fatigue, nausea, and vomiting has been reported by Situ et al. [182] Essiac [183] has been used increasingly for relief of symptoms in breast cancer patients; however, no significant effect in improving quality of life and mood states was found in a retrospective cohort study of breast cancer survivors.

Mind body medicine, a part of non-pharmacologic CAM that enables the mind to affect body functions, is being used increasingly by breast cancer patients [184]. A recent study reported $64.2 \%$ of breast cancer patients practiced mind body techniques following their diagnosis and this practice was associated with Hispanic race, higher education, low income, and other CAM use [185]. Meditation and yoga are two such areas that have been researched more than other techniques. Thus far studies of meditation and yoga in cancer have focused mainly on patients' quality of life [186-193]; while some studies have looked into symptoms like fatigue [194]. Mindfulness has been reported to improve cognitive functions in healthy and diseased populations [195]; however, studies of the effects of CAM techniques' on cognitive dysfunction in the breast cancer population are needed.

Mindfulness-based stress reduction (MBSR), a program that includes meditation and yoga postures, reported lower levels of total mood disturbance and distress [196] the effects of which persisted until the 12-month assessment [187]; and significant improvements in mood, sleep quality, and fatigue in a mixed cancer population [197]. A recent randomized controlled trial of MBSR program for 6 weeks in breast cancer survivors reported reduced anxiety, depression, and fear of recurrence and better perception of physical functioning [191].

Significant improvements have been reported in breast cancer 
survivors' persistent fatigue scores after a 12-week practice of yoga [194]. Another trial of yoga has been reported to led to significantly better general health perception and physical functioning scores, higher levels of intrusive thoughts, and greater benefit finding in women with breast cancer stages 0-III undergoing radiation [198]; reduced fatigue and insomnia in stage II and III breast cancer patients compared to a brief supportive therapy group [199]; better QOL, social and emotional well-being, and spirituality in women with breast cancer from various ethnic backgrounds after chemotherapy [200]; better QOL and mood, less nausea and vomiting [201]; and a smaller decrease in natural killer (NK) cell percentages from pre- to postsurgery and postchemotherapy [202]. A similar study of yoga in women with breast cancer undergoing radiotherapy showed significantly less anxiety, depression, perceived stress, and DNA damage at the end of the treatment in the yoga group versus the control group receiving supportive counseling [203]

Other yoga programs, such as Iyengar yoga (IY) practice in breast cancer survivors, have shown an improvement in fatigue scores as well as emotional well-being [186] and improved pain and vitality scores in addition to other quality of life indices [204]. Similarly, better mental health scores and greater positive affect from a restorative yoga practice in women during active treatment [189]; reduced joint pains, fatigue, and sleep disturbance after practice of "Yoga of Awareness" program in survivors of stages IA-IIB breast cancer [188]; and reduced pain and fatigue in women with metastatic breast cancer after practicing similar yoga techniques have also been reported [205]. Another style, Viniyoga, has been observed to significantly improve fatigue in obese breast cancer survivors [206].

Acupuncture is included in mind body as well as manipulative techniques and it has been reported to reduce fatigue along with psychosocial distress in a sample of advanced breast and ovarian cancer patients [207]. One randomized controlled trial of polarity therapy reported significant reduction in fatigue in breast cancer patients undergoing radiation. Hypnosis, another mind body technique, in combination with cognitive behavioral therapy, has been reported to prevent the increase of fatigue increase compared to standard medical care during radiation therapy in breast cancer patients [208]. The same investigators have also observed reduced fatigue in women who underwent lumpectomy for breast cancer following a 15-minute presurgery hypnosis session compared to an attention control group [209]. Practice of a Chinese technique, tai chi, has been reported to increase functional capacity in terms of increased aerobic capacity, muscular strength, and flexibility compared to the control group and as well as improved health-related QOL and self esteem [163,164]. However, other studies of tai chi intervention have not provided consistent results and further research is needed [210].

Overall, integrative medicine research for breast cancer patients has grown in the past decade, yet there is heterogeneity in terms of the study design, the type and length of intervention programs, and the measures used to assess outcomes. Larger studies are needed to confirm the effects of many integrative medicine techniques on common symptoms of breast cancer treatment.

\section{Clinical Perspectives}

Assessment and treatment of symptoms is of utmost importance to the oncologist. In addition to affecting quality of life and activities of daily living, symptoms during treatment can lead to dose-reductions, non-compliance, and ultimately affect outcome. The oncologist assessing a complaint of side effects must obtain a thorough history including onset of the symptom in relation to the timing of the treatment, severity of the symptom, extent of symptom interference with activities of daily living, and extent of symptom progression or worsening with time. Some symptoms needing assessment may also appear months or years after treatment has ended.

Symptoms are typically assessed by self-report on a visual analog scale by validated symptom inventory measures used within the clinic. Blood tests may also be employed if anemia, hypothyroidism, or low Vitamin D is suspected. Additional analytic techniques may also be used including echocardiograms for cardiotoxicity, neuropsychological tests for cognitive difficulties and Dual-Energy X-Ray Absorptiometry (DEXA) scans to evaluate bone density.

It is important to inquire about patterns of co-occurring symptoms and obtain details of symptom cluster manifestations. New diagnoses, whether medical or psychiatric, should be considered as possible contributors to side effects. Therefore, communication with the patient's primary care physician can often offer insight that may be useful in understanding the complaint of a new side-effect. Additionally, a full list of medications can also be helpful in understanding what, besides cancer treatments, may be contributing to the symptom burden, as well as a clear assessment of the patient's nutritional status. For example, chemotherapy-associated nausea and vomiting, and mucocitis can lead to poor oral intake, weight loss and a cascade effect of related symptomatology such as loss of energy or fatigue, depression and anxiety.

Management of symptoms is always individualized to the patient depending on their specific circumstances. Methods of possibly reducing symptom burden are included within this review, and every opportunity should be taken to alleviate symptoms to limit dose reductions to treatments, particularly in the curative setting. This underscores the need for more symptom management research-which is becoming increasingly important for continuing the improvement of quality of cancer.

\section{Conclusion}

This review highlights many areas of symptom management for breast cancer which have been recently addressed with systematic research methods. While tremendous progress has been made in the symptom management field, additional rigorous research is needed so that clinical guidelines in specific symptom management areas can be developed or refined. This review underscores the need for more symptom management research-which is becoming increasingly important for improving quality of life for breast cancer patients and involves close collaboration between oncologists and symptom management clinical researchers.

\section{Acknowledgement}

The research described in this publication was made possible by a grant from the $\mathrm{NCl}$ (Grant No. 1R25CA102618).

\section{References}

1. Janelsins MC, Kohli S, Mohile SG, Usuki K, Ahles TA, et al. (2011) An update on cancer- and chemotherapy-related cognitive dysfunction: current status. Semin Oncol 38: 431-438.

2. Ahles TA, Saykin AJ, McDonald BC, Li Y, Furstenberg CT, et al. (2010) Longitudinal Assessment of Cognitive Changes Associated With Adjuvan Treatment for Breast Cancer: Impact of Age and Cognitive Reserve. J Clin Oncol 28: 4434-4440.

3. Ahles TA, Saykin AJ, Furstenberg CT, Cole B, Mott LA, et al. (2002) Neuropsychologic impact of standard-dose systemic chemotherapy in longterm survivors of breast cancer and lymphoma. J Clin Oncol 20: 485-493. 
4. Ahles TA, Saykin AJ (2002) Breast cancer chemotherapy-related cognitive dysfunction. Clin Breast Cancer 3 Suppl 3: S84-S90.

5. Ahles TA, Saykin A (2001) Cognitive effects of standard-dose chemotherapy in patients with cancer. Cancer Invest 19: 812-820.

6. Brezden CB, Phillips KA, Abdolell M, Bunston T, Tannock IF (2000) Cognitive function in breast cancer patients receiving adjuvant chemotherapy. J Clin Oncol 18: 2695-2701.

7. Wefel JS, Vardy J, Ahles T, Schagen SB (2011) International Cognition and Cancer Task Force recommendations to harmonise studies of cognitive function in patients with cancer. Lancet Oncol 12: 703-708.

8. Wefel JS, Saleeba AK, Buzdar AU, Meyers CA (2010) Acute and late onse cognitive dysfunction associated with chemotherapy in women with breas cancer. Cancer 116: 3348-3356.

9. Wefel JS, Lenzi R, Theriault RL, Davis RN, Meyers CA (2004) The cognitive sequelae of standard-dose adjuvant chemotherapy in women with breas carcinoma: results of a prospective, randomized, longitudinal trial. Cancer 100 2292-2299.

10. Wieneke MH, Dienst ER (1995) Neuropsychological assessment of cognitive functioning following chemotherapy for breast cancer. Psycho-Oncology 4: 61 66.

11. Wagner L, Sweet J, Butt Z , Lai J, Cella D (2009) Measuring Patient SelfReported Cognitive Function: Development of the Functional Assessment of Cancer Therapy-Cognitive Function Instrument. Journal of Supportive Oncology 7: 32-39.

12. Vardy J, Wong K, Yi Q, Park A, Maruff P, et al. (2006) Assessing cognitive function in cancer patients. Supportive Care in Cancer 14: 1111-1118.

13. van Dam FSAM, Boogerd W (1998) Impairment of cognitive function in women receiving adjuvant treatment for high-risk breast cancer: high-dose versus standard-dose chemotherapy. J Natl Cancer Inst 90: 210-218.

14. Tannock IF, Ahles TA, Ganz PA, Van Dam FS (2004) Cognitive impairment associated with chemotherapy for cancer: report of a workshop. J Clin Oncol 22: 2233-2239.

15. Schagen SB, Vardy J (2007) Cognitive dysfunction in people with cancer Lancet Oncol 8: 852-853.

16. Schagen SB, van Dam FS, Muller MJ, Boogerd W, Lindeboom J, et al. (1999) Cognitive deficits after postoperative adjuvant chemotherapy for breast carcinoma. Cancer 85: 640-650.

17. Schagen SB, van Dam FS (2006) Does cognitive impairment after chemotherapy for breast cancer improve over time or does practice make perfect? J Clin Oncol 24: 5170-5171; author reply 5171-5172.

18. Morrow GR, Shelke AR, Roscoe JA, Hickok JT, Mustian K (2005) Management of cancer-related fatigue. Cancer Invest 23: 229-239.

19. Mustian KM, Peppone LJ, Palesh OG, Janelsins MC, Mohile SG, et al. (2009) Exercise and cancer-related fatigue. US Oncol 5: 20-23.

20. Jacobsen PB, Donovan KA, Small BJ, Jim HS, Munster PN, et al. (2007) Fatigue after treatment for early stage breast cancer: a controlled comparison. Cancer 110: 1851-1859.

21. Hickok JT, Roscoe JA, Morrow GR, Mustian K, Okunieff P, et al. (2005) Frequency, severity, clinical course, and correlates of fatigue in 372 patients during 5 weeks of radiotherapy for cancer. Cancer 104: 1772-1778.

22. Fan HG, Houédé-Tchen N, Yi QL, Chemerynsky I, Downie FP, et al. (2005) Fatigue, menopausal symptoms, and cognitive function in women after adjuvant chemotherapy for breast cancer: 1- and 2-year follow-up of a prospective controlled study. J Clin Oncol 23: 8025-8032.

23. Palesh OG, Roscoe JA, Mustian KM, Roth T, Savard J, et al. (2010) Prevalence, demographics, and psychological associations of sleep disruption in patients with cancer: University of Rochester Cancer Center-Community Clinical Oncology Program. J Clin Oncol 28: 292-298.

24. Baum M, Buzdar A, Cuzick J, Forbes J, Houghton J, et al. (2003) Anastrozole alone or in combination with tamoxifen versus tamoxifen alone for adjuvant treatment of postmenopausal women with early-stage breast cancer: results of the ATAC (Arimidex, Tamoxifen Alone or in Combination) trial efficacy and safety update analyses. Cancer 98: 1802-1810.

25. Buzdar A, Howell A, Cuzick J, Wale C, Distler W, et al. (2006) Comprehensive side-effect profile of anastrozole and tamoxifen as adjuvant treatment for earlystage breast cancer: long-term safety analysis of the ATAC trial. Lancet Oncol 7: 633-643.

26. Coates AS, Keshaviah A, Thürlimann B, Mouridsen H, Mauriac L, et al. (2007) Five years of letrozole compared with tamoxifen as initial adjuvant therapy for postmenopausal women with endocrine-responsive early breast cancer: update of study BIG 1-98. J Clin Oncol 25: 486-492.

27. Mouridsen H, Giobbie-Hurder A, Goldhirsch A, Thürlimann B, Paridaens R, et al. (2009) Letrozole therapy alone or in sequence with tamoxifen in women with breast cancer. N Engl J Med 361: 766-776.

28. Diller L, Chow EJ, Gurney JG, Hudson MM, Kadin-Lottick NS, et al. (2009) Chronic disease in the Childhood Cancer Survivor Study cohort: a review of published findings. J Clin Oncol 27: 2339-2355.

29. Mertens AC, Yasui Y, Neglia JP, Potter JD, Nesbit ME Jr, et al. (2001) Late mortality experience in five-year survivors of childhood and adolescent cancer: the Childhood Cancer Survivor Study. J Clin Oncol 19: 3163-3172.

30. Chen Z, Maricic M, Pettinger M, Ritenbaugh C, Lopez AM, et al. (2005) Osteoporosis and rate of bone loss among postmenopausal survivors of breast cancer. Cancer 104: 1520-1530.

31. Lindsey AM, Gross G, Twiss J, Waltman N, Ott C, et al. (2002) Postmenopausa survivors of breast cancer at risk for osteoporosis: nutritional intake and body size. Cancer Nurs 25: 50-56.

32. Twiss JJ, Waltman N, Ott CD, Gross GJ, Lindsey AM, et al. (2001) Bone mineral density in postmenopausal breast cancer survivors. J Am Acad Nurse Pract 13: 276-284

33. Wang XS, Shi Q, Williams LA, Mao L, Cleeland CS, et al. (2010) Inflammatory cytokines are associated with the development of symptom burden in patients with NSCLC undergoing concurrent chemoradiation therapy. Brain Behav Immun 24: 968-974.

34. Pusztai L, Mendoza TR, Reuben JM, Martinez MM, Willey JS, et al. (2004) Changes in plasma levels of inflammatory cytokines in response to paclitaxe chemotherapy. Cytokine 25: 94-102

35. Cleeland CS, Bennett GJ, Dantzer R, Dougherty PM, Dunn AJ, et al. (2003) Are the symptoms of cancer and cancer treatment due to a shared biologic mechanism? A cytokine-immunologic model of cancer symptoms. Cancer 97 2919-2925.

36. Sprod LK, Palesh OG, Janelsins MC, Peppone LJ, Heckler CE, et al. (2010) Exercise, sleep quality, and mediators of sleep in breast and prostate cance patients receiving radiation therapy. Community Oncol 7: 463-471.

37. Janelsins MC, Mustian KM, Palesh OG, Mohile SG, Peppone LJ, et al. (2011) Differential expression of cytokines in breast cancer patients receiving different chemotherapies: implications for cognitive impairment research. Support Care Cancer [Epub ahead of print]

38. Janelsins MC, Kohli S, Mohile SG, Usuki K, Ahles TA, et al. (2010) An Update on Cancer-and Chemotherapy-Related Cognitive Difficulties: State of the Field and Possible Mechanisms. Sem Onc [In Press].

39. Wood LJ, Nail LM, Gilster A, Winters KA, Elsea CR (2006) Cancer chemotherapyrelated symptoms: evidence to suggest a role for proinflammatory cytokines. Oncol Nurs Forum 33: 535-542.

40. Ahles TA, Saykin AJ (2007) Candidate mechanisms for chemotherapy-induced cognitive changes. Nat Rev Cancer 7: 192-201.

41. Bower JE, Ganz PA, Irwin MR, Arevalo JM, Cole SW (2011) Fatigue and gene expression in human leukocytes: increased NF-kappaB and decreased glucocorticoid signaling in breast cancer survivors with persistent fatigue. Brain Behav Immun 25: 147-150.

42. Bower JE, Ganz PA, Tao ML, Hu W, Belin TR, et al. (2009) Inflammatory biomarkers and fatigue during radiation therapy for breast and prostate cancer. Clin Cancer Res 15: 5534-5540. 
Citation: Janelsins MC, Mustian KM, Peppone LJ, Sprod LK, Shayne M, et al. (2011) Interventions to Alleviate Symptoms Related to Breast Cancer Treatments and Areas of Needed Research. J Cancer Sci Ther S2. doi:10.4172/1948-5956.S2-001

43. Bower JE ( 2007) Cancer-related fatigue: links with inflammation in cancer patients and survivors. Brain Behav Immun 21: 863-871.

44. Collado-Hidalgo A, Bower JE, Ganz PA, Cole SW, Irwin MR (2006) Inflammatory biomarkers for persistent fatigue in breast cancer survivors. Clin Cancer Res 12: $2759-2766$

45. Reid-Arndt SA, Yee A, Perry MC, Hsieh C (2009) Cognitive and psychological factors associated with early posttreatment functional outcomes in breast cancer survivors. J Psychosoc Oncol 27: 415-434.

46. Ma AM, Barone J, Wallis AE, Wu NJ, Garcia LB, et al. 2008) Noncompliance with adjuvant radiation, chemotherapy, or hormonal therapy in breast cancer patients. Am J Surg 196: 500-504.

47. Bruera E, Valero V, Driver L, Shen L, Willey J, et al. (2006) Patient-controlled methylphenidate for cancer fatigue: a double-blind, randomized, placebocontrolled trial. J Clin Oncol 24: 2073-2078.

48. Lower EE, Fleishman S, Cooper A, Zeldis J, Faleck H, et al. (2009) Efficacy of dexmethylphenidate for the treatment of fatigue after cancer chemotherapy: a randomized clinical trial. J Pain Symptom Manage 38: 650-662.

49. Auret KA, Schug SA, Bremner AP, Bulsara M (2009) A randomized, doubleblind, placebo-controlled trial assessing the impact of dexamphetamine on fatigue in patients with advanced cancer. J Pain Symptom Manage 37: 613-

50. Kohli S, Fisher SG, Tra Y, Adams MJ, Mapstone ME, et al. (2009) The effect of modafinil on cognitive function in breast cancer survivors. Cancer 115: 26052616

51. Jean-Pierre P, Morrow GR, Roscoe JA, Heckler C, Mohile S, et al. (2010) A phase 3 randomized, placebo-controlled, double-blind, clinical trial of the effect of modafinil on cancer-related fatigue among 631 patients receiving chemotherapy: a University of Rochester Cancer Center Community Clinical Oncology Program Research base study. Cancer 116: 3513-3520.

52. Roscoe JA, Morrow GR, Hickok JT, Mustian KM, Griggs JJ, et al. (2005) Effect of paroxetine hydrochloride (Paxil) on fatigue and depression in breast cancer patients receiving chemotherapy. Breast Cancer Res Treat 89: 243-249.

53. Morrow GR, Hickok JT, Roscoe JA, Raubertas RF, Andrews PL, et al. (2003) Differential effects of paroxetine on fatigue and depression: a randomized, double-blind trial from the University of Rochester Cancer Center Community Clinical Oncology Program. J Clin Oncol 21: 4635-4641.

54. Pezzella G, Moslinger-Gehmayr R, Contu A (2001) Treatment of depression in patients with breast cancer: a comparison between paroxetine and amitriptyline. Breast Cancer Res Treat 70: 1-10.

55. Crew KD, Shane E, Cremers S, McMahon DJ, Irani D, et al. (2009) High prevalence of vitamin $\mathrm{D}$ deficiency despite supplementation in premenopausal women with breast cancer undergoing adjuvant chemotherapy. J Clin Oncol 27: 2151-2156.

56. Peppone LJ, Huston AJ, Reid ME, Rosier RN, Zakharia Y, et al. (2011) The effect of various vitamin $\mathrm{D}$ supplementation regimens in breast cancer patients. Breast Cancer Res Treat 127: 171-177.

57. Shapiro CL, Manola J, Leboff M (2001) Ovarian failure after adjuvan chemotherapy is associated with rapid bone loss in women with early-stage breast cancer. J Clin Oncol 19: 3306-3311.

58. Hirbe A, Morgan EA, Uluckan O, Weilbaecher K (2006) Skeletal complications of breast cancer therapies. Clin Cancer Res 12: 6309s-6314s.

59. Eastell R, Hannon RA, Cuzick J, Dowsett M, Clack G, et al. (2006) Effect of an aromatase inhibitor on bmd and bone turnover markers: 2-year results of the Anastrozole, Tamoxifen, Alone or in Combination (ATAC) trial (18233230). J Bone Miner Res 21: 1215-1223.

60. Confavreux CB, Fontana A, Guastalla JP, MunozF, Brun J, etal. (2007) Estrogendependent increase in bone turnover and bone loss in postmenopausal women with breast cancer treated with anastrozole. Prevention with bisphosphonates. Bone 41: 346-352.

61. Eastell R, Adams JE, Coleman RE, Howell A, Hannon RA, et al. (2008) Effect of anastrozole on bone mineral density: 5 -year results from the anastrozole, tamoxifen, alone or in combination trial 18233230. J Clin Oncol 26: 1051-1057.
62. Chen Z, Maricic M, Aragaki AK, Mouton C, Arendell L, et al. (2009) Fracture risk increases after diagnosis of breast or other cancers in postmenopausal women: results from the Women's Health Initiative. Osteoporos Int 20: 527 536

63. Chen Z, Maricic M, Bassford TL, Pettinger M, Ritenbaugh C, et al. (2005) Fracture risk among breast cancer survivors: results from the Women's Health Initiative Observational Study. Arch Intern Med 165: 552-558.

64. Kanis JA, McCloskey EV, Powles T, Paterson AH, Ashley S, et al. (1999) A high incidence of vertebral fracture in women with breast cancer. $\mathrm{Br} \mathrm{J}$ Cancer 79: 1179-1181.

65. Leibson CL, Tosteson AN, Gabriel SE, Ransom JE, Melton LJ (2002) Mortality, disability, and nursing home use for persons with and without hip fracture: a population-based study. J Am Geriatr Soc 50: 1644-1650.

66. Magaziner J, Hawkes W, Hebel JR, Zimmerman SI, Fox KM, et al. (2000) Recovery from hip fracture in eight areas of function. J Gerontol A Biol Sci Med Sci 55: M498-507.

67. Marcus R, Feldman D, Kelsey JL (2001) Osteoporosis. 2nd ed. San Diego, CA Academic Press

68. Salkeld G, Cameron ID, Cumming RG, Easter S, Seymour J, et al. (2000) Quality of life related to fear of falling and hip fracture in older women: a time trade off study. BMJ 320: 341-346.

69. Lips P (2001) Vitamin D deficiency and secondary hyperparathyroidism in the elderly: consequences for bone loss and fractures and therapeutic implications. Endocr Rev 22: 477-501.

70. Cranney A, Horsley T, O'Donnell S, Weiler H, Puil L, et al. (2007) Effectiveness and safety of vitamin $D$ in relation to bone health. Evid Rep Technol Assess (Full Rep) 1-235

71. Bischoff-Ferrari HA, Willett WC, Wong JB, Giovannucci E, Dietrich T, et al. (2005) Fracture prevention with vitamin D supplementation: a meta-analysis of randomized controlled trials. JAMA 293: 2257-2264.

72. Bischoff-Ferrari HA, Willett WC, Wong JB, Stuck AE, Staehelin HB, et al. (2009) Prevention of nonvertebral fractures with oral vitamin $D$ and dose dependency: a meta-analysis of randomized controlled trials. Arch Intern Med 169: 551-561.

73. Chapuy MC, Arlot ME, Duboeuf F, Brun J, Crouzet B, et al. (1992) Vitamin D3 and calcium to prevent hip fractures in the elderly women. N Engl J Med 327 1637-1642.

74. Dawson-Hughes B, Harris SS, Krall EA, Dallal GE (1997) Effect of calcium and vitamin $D$ supplementation on bone density in men and women 65 years of age or older. N Engl J Med 337: 670-676.

75. Heikkinen AM, Parviainen M, Niskanen L, Komulainen M, Tuppurainen MT et al. (1997) Biochemical bone markers and bone mineral density during postmenopausal hormone replacement therapy with and without vitamin D3: prospective, controlled, randomized study. J Clin Endocrinol Metab 82: 2476 2482

76. Meyer HE, Smedshaug GB, Kvaavik E, Falch JA, Tverdal A, et al. (2002) Can vitamin $D$ supplementation reduce the risk of fracture in the elderly? $A$ randomized controlled trial. J Bone Miner Res 17: 709-715.

77. Seamans KM, Hill TR, Wallace JM, Horigan G, Lucey AJ, et al. (2010) Cholecalciferol supplementation throughout winter does not affect markers of bone turnover in healthy young and elderly adults. J Nutr 140: 454-460.

78. Meier C, Woitge HW, Witte K, Lemmer B, Seibel MJ (2004) Supplementation with oral vitamin D3 and calcium during winter prevents seasonal bone loss: a randomized controlled open-label prospective trial. J Bone Miner Res 19: 1221 1230.

79. Mocanu V, Stitt PA, Costan AR, Voroniuc O, Zbranca E, et al. (2009) Long-term effects of giving nursing home residents bread fortified with 125 microg (5000 IU) vitamin $\mathrm{D}(3)$ per daily serving. Am J Clin Nutr 89: 1132-1137.

80. Cooper L, Clifton-Bligh PB, Nery ML, Figtree G, Twigg S, et al. (2003) Vitamin $\mathrm{D}$ supplementation and bone mineral density in early postmenopausal women. Am J Clin Nutr 77: 1324-1329. 
Citation: Janelsins MC, Mustian KM, Peppone LJ, Sprod LK, Shayne M, et al. (2011) Interventions to Alleviate Symptoms Related to Breast Cancer Treatments and Areas of Needed Research. J Cancer Sci Ther S2. doi:10.4172/1948-5956.S2-001

81. Patel R, Collins D, Bullock S, Swaminathan R, Blake GM, et al. (2001) The effect of season and vitamin $D$ supplementation on bone mineral density in healthy women: a double-masked crossover study. Osteoporos Int 12: 319325.

82. Peacock M, Liu G, Carey M, McClintock R, Ambrosius W, et al. (2000) Effect of calcium or $25 \mathrm{OH}$ vitamin D3 dietary supplementation on bone loss at the hip in men and women over the age of 60. J Clin Endocrinol Metab 85: 3011-3019.

83. Adams JS, Kantorovich V, Wu C, Javanbakht M, Hollis BW (1999) Resolution of vitamin $\mathrm{D}$ insufficiency in osteopenic patients results in rapid recovery of bone mineral density. J Clin Endocrinol Metab 84: 2729-2730.

84. Geller JL, Hu B, Reed S, Mirocha J, Adams JS (2008) Increase in bone mass after correction of vitamin D insufficiency in bisphosphonate-treated patients. Endocr Pract 14: 293-297.

85. Bacon CJ, Gamble GD, Horne AM, Scott MA, Reid IR (2009) High-dose oral vitamin D3 supplementation in the elderly. Osteoporos Int 20: 1407-1415.

86. Malhotra N, Mithal A, Gupta S, Shukla M, Godbole M (2009) Effect of vitamin D supplementation on bone health parameters of healthy young Indian women. Arch Osteoporos 4: 47-53.

87. Mastaglia SR, Mautalen CA, Parisi MS, Oliveri B (2006) Vitamin D2 dose required to rapidly increase $25 \mathrm{OHD}$ levels in osteoporotic women. Eur $\mathrm{J}$ Clin Nutr 60: 681-687.

88. Falleti MG, Sanfilippo A, Maruff P, Weih L, Phillips KA (2005) The nature and severity of cognitive impairment associated with adjuvant chemotherapy in women with breast cancer: a meta-analysis of the current literature. Brain Cogn 59: 60-70.

89. Annweiler C, Schott AM, Berrut G, Chauviré V, Le Gall D, et al. (2010) Vitamin $D$ and ageing: neurological issues. Neuropsychobiology 62: 139-150.

90. Annweiler C, Schott AM, Rolland Y, Blain H, Herrmann FR, et al. (2010) Dietary intake of vitamin $D$ and cognition in older women: a large population-based study. Neurology 75: 1810-1816.

91. Kalueff AV, Tuohimaa $P$ (2007) Neurosteroid hormone vitamin D and its utility in clinical nutrition. Curr Opin Clin Nutr Metab Care 10: 12-19.

92. Annweiler C, Allali G, Allain P, Bridenbaugh S, Schott AM, et al. (2009) Vitamin $\mathrm{D}$ and cognitive performance in adults: a systematic review. Eur J Neurol 16: 1083-1089.

93. Annweiler C, Schott AM, Allali G, Bridenbaugh SA, Kressig RW, et al. (2010) Association of vitamin $D$ deficiency with cognitive impairment in older women: cross-sectional study. Neurology 74: 27-32.

94. Felson DT, Cummings SR (2005) Aromatase inhibitors and the syndrome of arthralgias with estrogen deprivation. Arthritis Rheum 52: 2594-2598.

95. Crew KD, Greenlee H, Capodice J, Raptis G, Brafman L, et al. (2007) Prevalence of joint symptoms in postmenopausal women taking aromatase inhibitors for early-stage breast cancer. J Clin Oncol 25: 3877-3883.

96. Partridge AH, LaFountain A, Mayer E, Taylor BS, Winer E, et al. (2008) Adherence to initial adjuvant anastrozole therapy among women with earlystage breast cancer. J Clin Oncol 26: 556-562.

97. Dent S, DiValentin T, Vandermeer L, Spaans J, Verma S (2006) Long term toxicities in women with early stage breast cancer treated with aromatase inhibitors: data from a tertiary care center. Breast Cancer Res Treat 100 (suppl 1): S190.

98. Fontaine C, Meulemans A, Huizing M, Collen C, Kaufman L, et al. (2008) Tolerance of adjuvant letrozole outside of clinical trials. Breast 17: 376-381.

99. Prieto-Alhambra D, Javaid MK, Servitja S, Arden NK, Martinez-García M, et al (2011) Vitamin D threshold to prevent aromatase inhibitor-induced arthralgia: a prospective cohort study. Breast Cancer Res Treat 125: 869-878.

100. Chen MH, Colan SD, Diller L (2011) Cardiovascular disease: cause of morbidity and mortality in adult survivors of childhood cancers. Circ Res 108: 619-628.

101. Smith LA, Cornelius VR, Plummer CJ, Levitt G, Verrill M, et al. (2010) Cardiotoxicity of anthracycline agents for the treatment of cancer: systematic review and meta-analysis of randomised controlled trials. BMC Cancer 10 337.

102. Rayson D, Richel D, Chia S, Jackisch C, van der Vegt S, et al. (2008) Anthracycline-trastuzumab regimens for HER2/neu-overexpressing breas cancer: current experience and future strategies. Ann Oncol 19: 1530-1539.

103. Seidman A, Hudis C, Pierri MK, Shak S, Paton V, et al. (2002) Cardiac dysfunction in the trastuzumab clinical trials experience. J Clin Oncol 20 1215-1221.

104. Manson JE (2010) Vitamin D and the heart: why we need large-scale clinical trials. Cleve Clin J Med 77: 903-910.

105.Stevens PE, Dibble SL, Miaskowski C (1995) Prevalence, characteristics and impact of postmastectomy pain syndrome: an investigation of women's experiences. Pain 61: 61-68.

106. Carpenter JS, Andrykowski MA, Sloan P, Cunningham L, Cordova MJ, et al (1998) Postmastectomy/postlumpectomy pain in breast cancer survivors. J Clin Epidemiol 51: 1285-1292.

107. Tasmuth T, Blomqvist C, Kalso E (1999) Chronic post-treatment symptoms in patients with breast cancer operated in different surgical units. Eur $\mathrm{J}$ Surg Oncol 25: 38-43.

108. Stillman M (2006) Clinical approach to patients with neuropathic pain. Cleve Clin J Med 73: 726-728, 729-730, 733-736 passim.

109. Patarica-Huber E, Boskov N, Pjevic M (2011) Multimodal approach to therapyrelated neuropathic pain in breast cancer. J BUON 16: 40-45.

110. Tasmuth T, Hartel B, Kalso E (2002) Venlafaxine in neuropathic pain following treatment of breast cancer. Eur J Pain 6: 17-24.

111. Amr YM, Yousef AA (2010) Evaluation of efficacy of the perioperative administration of Venlafaxine or gabapentin on acute and chronic postmastectomy pain. Clin J Pain 26: 381-385.

112. Fassoulaki A, Patris K, Sarantopoulos C, Hogan Q (2002) The analgesic effect of gabapentin and mexiletine after breast surgery for cancer. Anesth Analg 95 985-991, table of contents.

113. Grover VK, Mathew PJ, Yaddanapudi S, Sehgal S (2009) A single dose of preoperative gabapentin for pain reduction and requirement of morphine after total mastectomy and axillary dissection: randomized placebo-controlled double-blind trial. J Postgrad Med 55: 257-260.

114. Reuben SS, Makari-Judson G, Lurie SD (2004) Evaluation of efficacy of the perioperative administration of venlafaxine $\mathrm{XR}$ in the prevention of postmastectomy pain syndrome. J Pain Symptom Manage 27: 133-139.

115. Fassoulaki A, Sarantopoulos C, Melemeni A, Hogan Q (2000) EMLA reduces acute and chronic pain after breast surgery for cancer. Reg Anesth Pain Med 25: 350-355.

116. Fassoulaki A, Triga A, Melemeni A, Sarantopoulos C (2005) Multimoda analgesia with gabapentin and local anesthetics prevents acute and chronic pain after breast surgery for cancer. Anesth Analg 101: 1427-1432

117. Kairaluoma PM, Bachmann MS, Korpinen AK, Rosenberg PH, Pere PJ (2004) Single-injection paravertebral block before general anesthesia enhances analgesia after breast cancer surgery with and without associated lymph node biopsy. Anesth Analg 99: 1837-1843, table of contents.

118. Kairaluoma PM, Bachmann MS, Rosenberg PH, Pere PJ (2006) Preincisiona paravertebral block reduces the prevalence of chronic pain after breast surgery. Anesth Analg 103: 703-708.

119. Moller JF, Nikolajsen L, Rodt SA, Ronning H, Carlsson PS (2007) Thoracic paravertebral block for breast cancer surgery: a randomized double-blind study. Anesth Analg 105: 1848-1851, table of contents.

120. Coveney E, Weltz CR, Greengrass R, Iglehart JD, Leight GS, et al. (1998) Use of paravertebral block anesthesia in the surgical management of breas cancer: experience in 156 cases. Ann Surg 227: 496-501.

121.Boughey JC, Goravanchi F, Parris RN, Kee SS, Kowalski AM, et al. (2009) Prospective randomized trial of paravertebral block for patients undergoing breast cancer surgery. Am J Surg 198: 720-725. 
Citation: Janelsins MC, Mustian KM, Peppone LJ, Sprod LK, Shayne M, et al. (2011) Interventions to Alleviate Symptoms Related to Breast Cancer Treatments and Areas of Needed Research. J Cancer Sci Ther S2. doi:10.4172/1948-5956.S2-001

122. Mustian KM, Peppone LJ, Palesh OG, Janelsins MC, Purnell JQ, et al. (2010) Exercise and cancer-related fatigue. US Oncological Review 6: 20-23.

123. Mustian KM, Morrow GR, Carroll JK, Figueroa-Moseley CD, Jean-Pierre $P$ et al. (2007) Integrative nonpharmacologic behavioral interventions for the management of cancer-related fatigue. The Oncologist 12: 52-67.

124. Mustian KM, Sprod LK, Palesh OG, Peppone LJ, Janelsins MC, et al. (2009) Exercise for the management of side effects and quality of life among cancer survivors. Curr Sports Med Rep 8: 325-330.

125. Mustian KM, Griggs JJ, Morrow GR, McTiernan A, Roscoe JA, et al. (2006) Exercise and side effects among 749 patients during and after treatment for cancer: a University of Rochester Cancer Center Community Clinical Oncology Program Study. Supportive Care in Cancer 14: 732-741.

126. Mustian KM, Hofman M, Morrow GR (2006) Cancer-Related Fatigue and Shortness of Breath Among Cancer Survivors: A Prospective URCC CCOP Study. $\mathrm{NCl}$ Cancer Survivorship Conference.

127. Mustian KM, Katula J, Williams J, Moynihan JA, Morrow GR (2007) Tai Ch Chuan, immune function, and cardiorespiratory fitness among breast cancer survivors. Annals of Behavioral Medicine 33: 95

128. Mustian KM, Katula JA, Gill DL, Roscoe JA, Lang D, et al. (2004) Tai Ch Chuan, health-related quality of life and self-esteem: A randomized trial with breast cancer survivors. Support Care Cancer 12: 871-876.

129. Mustian KM, Katula JA, Zhao H (2006) A pilot study to assess the influence of tai chi chuan on functional capacity among breast cancer survivors. J Support Oncol 4: 139-145.

130. Mustian KM, Morrow GR, Williams J, Griggs JJ, Padmanaban D, et al. (2005) Relationships Between Cancer-Related Fatigue (CRF), Physical Activity (PA), and Immune Function (IF) Among Breast Cancer Patients. The Annals of Behavioral Medicine 29: 34.

131. Mustian KM, Palesh OG, Flecksteiner SA (2008) Tai Chi Chuan for breast cancer survivors. Med Sport Sci 52: 209-217.

132. Mustian KM, Peppone L, Darling TV, Palesh O, Heckler CE, et al. (2009) A 4-week home-based aerobic and resistance exercise program during radiation therapy: a pilot randomized clinical trial. J Support Oncol 7: 158-167.

133. Rodenhuis S, Huitema AD, van Dam FS, de Vries EG, Beijnen JH (2000) High-dose chemotherapy with peripheral blood progenitor cell transplantation in the adjuvant treatment of breast cancer. Cancer J 2: S125-130.

134. Galvao DA, Newton RU (2005) Review of exercise intervention studies in cancer patients. J Clin Oncol 23: 899-909.

135. Schmitz KH, Courneya KS, Matthews C, Demark-Wahnefried W, Galvão DA et al. (2010) American College of Sports Medicine roundtable on exercise guidelines for cancer survivors. Med Sci Sports Exerc 42: 1409-1426.

136. American College of Sports M. ACSM's Guidelines for exercise testing and prescription. Baltimore: Lippincott, Williams, \& Wilkins; 2010.

137. Knols R, Aaronson N, Uebelhart D, Fransen J, Aufdemkampe G (2005) Physical exercise in cancer patients during and after medical treatment: $A$ systematic review of randomized and controlled clinical trials. J Clin Oncol 23: 3830-3842.

138. Knols RH, de Bruin ED, Shirato K, Uebelhart D, Aaronson NK, et al. (2010) Physical activity interventions to improve daily walking activity in cancer survivors. BMC Cancer 10: 406.

139. Stevinson C, Lawlor DA, Fox KR (2004) Exercise interventions for cancer patients: systematic review of controlled trials. Cancer Causes Control 15: 1035-1056.

140. Schmitz K (2011) Physical activity and breast cancer survivorship. Recent Results Cancer Res 186: 189-215.

141. Schmitz KH, Holtzman J, Courneya KS, Masse LC, Duval S, et al. (2005) Controlled physical activity trials in cancer survivors: a systematic review and meta-analysis. Cancer Epidemiol, Biomarkers Prev 14: 1588-1595.

142. McNeely ML, Campbell KL, Rowe BH, Klassen TP, Mackey JR, et al. (2006)
Effects of exercise on breast cancer patients and survivors: a systematic review and meta-analysis. CMAJ 175: 34-41

143. Pekmezi DW, mark-Wahnefried W (2011) Updated evidence in support of diet and exercise interventions in cancer survivors. Acta Oncol 50: 167-178.

144.Duijts SF, Faber MM, Oldenburg HS, van Beurden M, Aaronson NK, et al (2011) Effectiveness of behavioral techniques and physical exercise on psychosocial functioning and health-related quality of life in breast cancer patients and survivors--a meta-analysis. Psychooncology 20: 115-126.

145. Arnold M, Taylor NF (2010) Does exercise reduce cancer-related fatigue in hospitalised oncology patients? A systematic review. Onkologie 33: 625-630.

146. Friedenreich CM (2011) Physical activity and breast cancer: review of the epidemiologic evidence and biologic mechanisms. Recent Results in Cancer Res 188: 125-139.

147. Pinto BM, Ciccolo JT (2011) Physical activity motivation and cance survivorship. Recent Results in Cancer Res 186: 367-387.

148. Lowe SS (2011) Physical activity and palliative cancer care. Recent Results in Cancer Res 186: 349-365

149. Cramp F, James A, Lambert $J$ (2010) The effects of resistance training on quality of life in cancer: a systematic literature review and meta-analysis. Supportive Care Cancer 18: 1367-1376.

150. Jones LW, Peppercom J, Scott JM, Battaglini C (2010) Exercise therapy in the management of solid tumors. Curr Treat Options Oncol 11: 45-58.

151. Mock V, Burke MB, Sheehan P, Creaton EM, Winningham ML, et al. (1994) A nursing rehabilitation program for women with breast cancer receiving adjuvant chemotherapy. Oncol Nurs Forum 21: 899-907.

152. Mock V, Dow KH, Meares CJ, Grimm PM, Dienemann JA, et al. (1997) Effects of exercise on fatigue, physical functioning, and emotional distress during radiation therapy for breast cancer. Oncol Nurs Forum 24: 991-1000.

153. Mock V, Frangakis C, Davidson N, Ropka ME, Pickett M, et al. (2005) Exercise manages fatigue during breast cancer treatment: a randomized controlled trial. Psychooncology 14: 464-477.

154. Courneya KS, Segal RJ, Mackey JR, Gelmon K, Reid RD, et al. (2007) Effects of aerobic and resistance exercise in breast cancer patients receiving adjuvant chemotherapy: a multicenter randomized controlled trial. J Clin Oncol 25: 4396-4404.

155. Pinto BM, Frierson GM, Rabin C, Trunzo JJ, Marcus BH, et al. (2005) Homebased physical activity intervention for breast cancer patients. J Clin Oncol 23 : 3577-3587.

156. Ahmed RL, Thomas W, Yee D, Schmitz KH (2006) Randomized controlled tria of weight training and lymphedema in breast cancer survivors. J Clin Oncol 24 2765-2772.

157. Winters-Stone KM, Dobek J, Nail L, Bennett JA, Leo MC, et al. (2011) Strength training stops bone loss and builds muscle in postmenopausal breast cance survivors: a randomized, controlled trial. Breast Cancer Res Treat 127: 447456.

158. Campbell A, Mutrie N, White F, McGuire F, Kearney N (2005) A pilot study of a supervised group exercise program as a rehabilitation treatment for women with breast cancer receiving adjuvant treatment. Eur J Oncol Nurs 9: 56-63.

159. Mustian KM, Peppone L, Darling T, Palesh O, Heckler C, et al. (2009) A 4-Week Home-Based Aerobic and Resistance Exercise Program During Radiation Therapy: a pilot randomized clinical trial. J Support Oncol 7: 158167.

160. Milne HM, Wallman KE, Gordon S, Courneya KS (2008) Effects of a combined aerobic and resistance exercise program in breast cancer survivors: a randomized controlled trial. Breast Cancer Res Treat 108: 279-288.

161. Janelsins MC, Davis PG, Wideman L, Katula JA, Sprod LK, et al. (2011) Effects of tai chi chuan on insulin and cytokine levels in a randomized controlled pilo study on breast cancer survivors. Clin Breast Cancer 11: 161-170.

162. Peppone LJ, Mustian KM, Janelsins MC, Palesh OG, Rosier RN, et al. (2010) 
Effects of a Structured Weight-Bearing Exercise Program on Bone Metabolism Among Breast Cancer Survivors: A Feasibility Trial. Clin Breast Cancer 10: 224-229.

163. Mustian KM, Katula JA, Zhao H (2006) A pilot study to assess the influence of tai chi chuan on functional capacity among breast cancer survivors. J Support Oncol 4: 139-145.

164. Mustian KM, Katula JA, Gill DL, Roscoe JA, Lang D, et al. (2004) Tai Chi Chuan, health-related quality of life and self-esteem: a randomized trial with breast cancer survivors. Support Care Cancer 12: 871-876.

165. Balducci L (2005) Epidemiology of cancer and aging. J Oncol Manag 14: 47 50

166. Mohile SG, Xian Y, Dale W, Fisher SG, Rodin M, et al. (2009) Association of a cancer diagnosis with vulnerability and frailty in older Medicare beneficiaries. Journal of the Natl Cancer Inst 101: 1206-1215.

167. Baker F, Haffer SC, Denniston M (2003) Health-related quality of life of cancer and noncancer patients in Medicare managed care. Cancer 97: 674-681.

168. Satariano WA, Ragheb NE, Branch LG, Swanson GM (1990) Difficulties in physical functioning reported by middle-aged and elderly women with breast cancer: a case-control comparison. J Gerontol 45: M3-11.

169. LaStayo PC, Marcus RL, Dibble LE, Smith SB, Beck SL (2011) Eccentric exercise versus usual-care with older cancer survivors: the impact on muscle and mobility--an exploratory pilot study. BMC Geriatr 11: 5.

170.Rydwik E, Lammes E, Frandin K, Akner G (2008) Effects of a physical and nutritional intervention program for frail elderly people over age 75 . A randomized controlled pilot treatment trial. Aging Clin Exp Res 20: 159-170.

171. Binder EF, Schechtman KB, Ehsani AA, Steger-May K, Brown M, et al. (2002) Effects of exercise training on frailty in community-dwelling older adults: results of a randomized, controlled trial. J Am Geriatr Soc 50: 1921-1928.

172. Faber MJ, Bosscher RJ, Chin APMJ, van Wieringen PC (2006) Effects of exercise programs on falls and mobility in frail and pre-frail older adults: A multicenter randomized controlled trial. Arch Phys Med Rehabil 87: 885-896.

173. Freiberger E, Menz HB, Abu-Omar K, Rutten A (2007) Preventing falls in physically active community-dwelling older people: a comparison of two intervention techniques. Gerontology 53: 298-305.

174. Sattin RW, Easley KA, Wolf SL, Chen Y, Kutner MH (2005) Reduction in fear of falling through intense tai chi exercise training in older, transitionally frail adults. J Am Geriatr Soc 53: 1168-1178.

175.American College of Sports Medicine, Chodzko-Zajko WJ, Proctor DN Fiatarone Singh MA, Minson CT,et al. (2009) American College of Sports Medicine position stand. Exercise and physical activity for older adults. Med Sci Sports Exerc 41: 1510-1530.

176. Panel on Prevention of Falls in Older Persons, American Geriatrics Society and British Geriatrics Society (2011) Summary of the Updated American Geriatrics Society/British Geriatrics Society Clinical Practice Guideline for Prevention of Falls in Older Persons. J Am Geriatr Soc 59: 148-157.

177. Whitehead S, Lavelle K (2009) Older breast cancer survivors' views and preferences for physical activity. Qual Health Res 19: 894-906.

178. Schmitz KH, Ahmed RL, Troxel AB, Cheville A, Lewis-Grant L, et al. (2010) Weight lifting for women at risk for breast cancer-related lymphedema: a randomized trial. JAMA 304: 2699-2705.

179. Astin JA, Reilly C, Perkins C, Child WL, Susan G (2006) Breast cancer patients' perspectives on and use of complementary and alternative medicine: a study by the Susan G. Komen Breast Cancer Foundation. J Soc Integr Oncol 4: 157-169.

180.Wanchai A, Armer JM, Stewart BR (2010) Complementary and alternative medicine use among women with breast cancer: a systematic review. Clin J Oncol Nurs 14: E45-55.

181. de Souza Fêde AB, Bensi CG, Trufelli DC, de Oliveira Campos MP, Pecoron PG, et al. (2007) Multivitamins do not improve radiation therapy-related fatigue: results of a double-blind randomized crossover trial. Am J Clin Onco 30: 432-436.
182. Situ HL, Lin Y, Chen QJ, Ou AH, Zhu HY, Liu PX (2005) Effect of Aifukang on quality of life of breast cancer patients treated with chemotherapy after operation. Journal of Guangzhou University of Traditional Chinese Medicine 22: $26-29$.

183.Zick SM, Sen A, Feng Y, Green J, Olatunde S, Boon H (2006) Trial of Essiac to ascertain its effect in women with breast cancer (TEA-BC). Journal of Alternative \& Complementary Medicine 12: 971-980.

184. Eschiti VS (2007) Lesson from comparison of CAM use by women with female-specific cancers to others: it's time to focus on interaction risks with CAM therapies. Integ Cancer Ther 6: 313-344.

185. Greenlee H, Kwan ML, Ergas IJ, et al. (2009) Complementary and alternative therapy use before and after breast cancer diagnosis: the Pathways Study. Breast Cancer Res Treat 117: 653-665.

186. Banasik J, Williams H, Haberman M, Blank SE, Bendel R (2011) Effect of lyengar yoga practice on fatigue and diurnal salivary cortisol concentration in breast cancer survivors. J Am Acad Nurse Pract 23: 135-142.

187. Carlson LE, Speca M, Faris P, Patel KD (2007) One year pre-post intervention follow-up of psychological, immune, endocrine and blood pressure outcomes of mindfulness-based stress reduction (MBSR) in breast and prostate cancer outpatients. Brain Behav Immun 21: 1038-1049.

188. Carson JW, Carson KM, Porter LS, Keefe FJ, Seewaldt VL (2009) Yoga of Awareness program for menopausal symptoms in breast cancer survivors: results from a randomized trial. Support Care Cancer 17: 1301-1309.

189.Danhauer SC, Mihalko SL, Russell GB, Campbell CR, Felder L, et al. (2009) Restorative yoga for women with breast cancer: findings from a randomized pilot study. Psycho-Oncology 18: 360-368.

190.Lengacher CA, Bennett MP, Kip KE, Gonzalez L, Jacobsen P, et al. (2006) Relief of symptoms, side effects, and psychological distress through use of complementary and alternative medicine in women with breast cancer Oncology Nursing Forum 33: 97-104.

191. Lengacher CA, Johnson-Mallard V, Post-White J, Moscoso MS, Jacobsen PB, et al. (2009) Randomized controlled trial of mindfulness-based stress reduction (MBSR) for survivors of breast cancer. Psychooncology 18: 12611272 .

192. Moadel A, Morgan C, Fatone A, Grennan J, Carter J, et al. (1999) Seeking meaning and hope: self-reported spiritual and existential needs among an ethnically-diverse cancer patient population. Psychooncology 8: 378-385

193. Chandwani KD, Thornton B, Perkins GH, Arun B, Raghuram NV, et al (2010) Yoga improves quality of life and benefit finding in women undergoing radiotherapy for breast cancer. J Soc Integr Oncol 8: 43-55.

194.Bower JE, Garet D, Sternlieb B (2011) Yoga for persistent fatigue in breast cancer survivors:results of a pilot study. Evid Based Complement Alternat Med (Epub) 2011.

195. Chiesa A, Calati R, Serretti A (2011) Does mindfulness training improve cognitive abilities? A systematic review of neuropsychological findings. Clinical Psycholoy Review 31: 449-464.

196. Speca M, Carlson LE, Goodey E, Angen M (2000) A randomized, wait-list controlled clinical trial: the effect of a mindfulness meditation-based stress reduction program on mood and symptoms of stress in cancer outpatients. Psychosom Med 62: 613-622.

197. Carlson LE, Garland SN (2005) Impact of mindfulness-based stress reduction (MBSR) on sleep, mood, stress and fatigue symptoms in cancer outpatients Int J Behav Med 12: 278-285.

198. Chandwani KD, Thornton B, Perkins GH, Arun B, Raghuram NV, et al (2010) Yoga improves quality of life and benefit finding in women undergoing radiotherapy for breast cancer. Journal of the Society for Integrative Oncology 8: 43-55.

199. Vadiraja HS, Raghavendra RM, Nagarathna R, Nagendra HR, Rekha M, et al. (2009) Effects of a yoga program on cortisol rhythm and mood states in early breast cancer patients undergoing adjuvant radiotherapy: a randomized controlled trial. Integ Cancer Ther 8: 37-46.

200. Moadel AB, Shah C, Wylie-Rosett J, Harris MS, Patel SR, et al. (2007) 
Citation: Janelsins MC, Mustian KM, Peppone LJ, Sprod LK, Shayne M, et al. (2011) Interventions to Alleviate Symptoms Related to Breast Cancer Treatments and Areas of Needed Research. J Cancer Sci Ther S2. doi:10.4172/1948-5956.S2-001

Randomized controlled trial of yoga among a multiethnic sample of breast cancer patients: effects on quality of life. Journal of Clin Oncol 25: 4387-4395.

201. Raghavendra RM, Nagarathna R, Nagendra HR, Gopinath KS, Srinath BS, et al. (2007) Effects of an integrated yoga programme on chemotherapy-induced nausea and emesis in breast cancer patients. European Journal of Cancer Care 16: 462-474

202. Rao RM, Telles S, Nagendra HR, Nagarathna R, Gopinath K, et al. (2008) Effects of yoga on natural killer cell counts in early breast cancer patients undergoing conventional treatment. Comment to: recreational music-making modulates natural killer cell activity, cytokines, and mood states in corporate employees Masatada Wachi, Masahiro Koyama, Masanori Utsuyama, Barry B. Bittman, Masanobu Kitagawa, Katsuiku Hirokawa Med Sci Monit, 2007; 13(2): CR57-70. Med Sci Monit 14: LE3-4.

203. Banerjee B, Vadiraj HS, Ram A, Rao R, Jayapal M, Gopinath KS, et al. (2007) Effects of an integrated yoga program in modulating psychological stress and radiation-induced genotoxic stress in breast cancer patients undergoing radiotherapy. Integ Cancer Ther 6: 242-250.

204. Speed-Andrews AE, Stevinson C, Belanger LJ, Mirus JJ, Courneya KS (2010) Pilot evaluation of an lyengar yoga program for breast cancer survivors. Cancer Nurs 33: 369-381.
205. Carson JW, Carson KM, Porter LS, Keefe FJ, Shaw H, et al. (2007)Yoga for women with metastatic breast cancer: results from a pilot study. J Pain Symptom Manage 33: 331-341.

206. Littman AJ, Bertram LC, Ceballos R, Ulrich CM, Ramaprasad J, et al. (2011) Randomized controlled trial of yoga in overweight and obese breast cancer survivors: effects on quality of life and anthropometric measures women. Supportive Care Cancer [Epub ahead of print].

207.Dean-Clower E, Doherty-Gilman AM, Keshaviah A, Baker F, Kaw C, et al. (2010) Acupuncture as palliative therapy for physical symptoms and quality of life for advanced cancer patients. Integ Cancer Ther 9: 158-167.

208. Montgomery GH, Kangas M, David D, Hallquist MN, Green S, et al. (2009) Fatigue during breast cancer radiotherapy: an initial randomized study of cognitive-behavioral therapy plus hypnosis. Health Psychology 28: 317-322.

209. Montgomery GH, Bovbjerg DH, Schnur JB, David D, Goldfarb A, et al. (2007) A randomized clinical trial of a brief hypnosis intervention to control side effects in breast surgery patients. J Natl Cancer Inst 99: 1304-1312.

210. Lee MS, Pittler MH, Ernst E (2007) Is Tai Chi an effective adjunct in cance care? A systematic review of controlled clinical trials. Supportive Care Cancer 15: 597-601.

This article was originally published in a special issue, Breast Cance handled by Editor(s). Dr. Pavol Zubor, Comenius University, Slovak republic 